\title{
One-month regular oral nutrition in alcoholic cirrbotic patients. Changes of nutritional status, hepatic function and serum lipid pattern
}

\author{
BY PHUONG NHI BORIES ${ }^{1}$ AND BERNARD CAMPILLO \\ ${ }^{1}$ Laboratoire Central and ${ }^{2}$ Service d'Hépato-gastroentérologie et Rééducation Digestive, \\ Hôpital Albert Chenevier, Créteil, France
}

(Received 10 January 1994 - Revised 21 April 1994 - Accepted 17 May 1994)

\begin{abstract}
The effect of a regular oral diet supplying $167 \mathrm{~kJ} / \mathrm{kg}$ per $\mathrm{d}(40 \mathrm{kcal} / \mathrm{kg}$ per d) on nutritional state, liver function and serum lipid profile was assessed in thirty severely malnourished alcoholic cirrhotic inpatients. Their diet was monitored by a trained dietitian and they were vigorously encouraged to eat all meals served. One month after their entry into the study, protein and energy intakes were significantly higher $(P<0.001)$ in keeping with an improvement of their nutritional status as evaluated by means of height-creatinine index, muscular mid-arm circumference, tricipital skinfold thickness $(P<0.01$ for all) and fat mass $(P<0.001)$. Assessment of liver function tests showed that levels of aspartate aminotransferase (EC 2.6.1.1), $\gamma$-glutamyl transferase $(E C$ 2.3.2.2) and bilirubin decreased $(P<0.05$, $P<0.02$ and $P<0.05$ respectively) while prothrombin time values increased $(P<0-05)$. Similarly, serum albumin increased modestly while transthyretin did not change. Orosomucoid and $C$-reactive protein decreased $(P<0.001$ and $P<0.01$ respectively), indicating an improvement of the inflammatory state. Apolipoprotein A1 and high-density-lipoprotein (HDL)-cholesterol correlated with several tests of liver function and improved significantly during the study period $(P<0.001$ and $P<0.02$ respectively). Moreover, changes in cholesterol and HDL-cholesterol correlated with those in transthyretin $(P<0.02$ and $P<0.05$ respectively). The changes in ApoAl and HDL-cholesterol were greater in patients whose fat mass increased significantly. Our findings show that adequate oral nutrition resulted in a better nutritional status in cirrhotics after 1 month of hospitalization. The serum lipid variables appeared to be more useful indicators of functional liver improvement than the classic liver function tests which rather indicate liver damage.
\end{abstract}

Alcoholic cirrhosis: Oral diet: Nutritional status: Liver function

Malnutrition is a common condition in patients with alcoholic liver cirrhosis and is associated with complications such as hepatic encephalopathy, severe infections and delayed healing of wounds (Mendenhall et al. 1986). The evidence relating malnutrition to a bad prognosis in these patients has led to a number of studies on the effects of nutritional support. Most investigators have administered enteral or parenteral supplementation, using vegetable- and animal-protein diets (Smith et al. 1982; Christie et al. 1985; Kearns et al. 1992) or branched-chain amino acid enriched solutions with either glucose or glucose-lipid mixtures (Keohane et al. 1983; Silk, 1988; Cabre et al. 1990). However, parenteral nutrition may lead to iatrogenic complications such as pneumothorax or catheter-related sepsis. Enteral feeding certainly offers a safer and more physiological alternative. Both techniques are somewhat invasive, require the patients to be hospitalized, and may be uncomfortable. They are necessarily performed on a short-term basis and no clear conclusions can be drawn on the beneficial effects of nutritional support. On the other hand, little information is available about the effects of oral supplementation. Recently, 
Hirsch et al. (1993) have obtained satisfactory results by orally supplementing ambulatory cirrhotic patients for 1 year with a casein-based enteral preparation.

The coexistence of malnutrition and liver failure naturally raises the question of whether improved nutritional status as a result of nutritional support may or may not be associated with improved hepatic function. Decreases in serum bilirubin are often obtained whereas changes in aminotransferases, alkaline phosphatase $(E C 3.1 .3 .1)$ or prothrombin time are reportedly controversial (Naveau et al. 1986; Kearns et al. 1992; Hirsch et al. 1993).

The present study was carried out in order to investigate the 1-month effect of a regular oral diet in alcoholic cirrhotic patients. The following questions were addressed: (1) was hospital diet alone, without any additional nutritional support, sufficient to obtain positive changes in anthropometric characteristics? (2) if so, were these changes associated with improved liver function tests? (3) since high-density-lipoprotein (HDL)-cholesterol and apolipoprotein A1 have been shown to correlate inversely with the degree of hepatic damage (Kanel et al. 1983; Cordova et al. 1984; Tateossian et al. 1985; Poynard et al. 1986), was there a net beneficial effect on the serum lipid profile?

\section{METHODS}

\section{Subjects}

Thirty cirrhotic patients (twenty-four males and six females) aged between 35 and 77 years (mean age 51.0 (SE 1.8 years)) who were admitted to our readaptive unit for liver diseases entered the study. The diagnosis of cirrhosis was proved histologically in fifteen cases and it was made from usual clinical and biological data in the remaining patients. All individuals had been hospitalized and had abstained from alcohol for 4 to 6 weeks preceding the entry into the study. They all had experienced severe complications of the disease, e.g. ascites, gastrointestinal bleeding, sepsis, hepatic encephalopathy. They were in stable clinical condition at the time of the study: they were neither septic nor febrile, and they suffered from no complications such as encephalopathy, acid-base imbalance or renal insufficiency. Thirteen patients showed ascites, were treated with diuretics and received albumin perfusion during the study. Spontaneous bacterial peritonitis occurred in two patients. The degree of liver damage was scored according to the classification of ChildPugh (Pugh et al. 1973).

\section{Dietary intake}

Before their admission to the unit, the patients' diets were not controlled. After their admission to the study the energy intake was monitored by a trained dietitian who gave them vigorous encouragement. The oral diet was conventional, providing about $167 \mathrm{~kJ} / \mathrm{kg}$ per d (40 kcal $/ \mathrm{kg}$ per d) with proportions of carbohydrate, lipid and protein respectively of 55,30 and $15 \%$ and was not enriched by any specific substrate. The diet was unrestricted except for $\mathrm{Na}$ and fluid in patients with ascites. The patients recorded the food intake with help from the dietitian. The composition of the diet was determined by means of food tables (Ostrowski, 1978). The energy intakes were calculated from five consecutive $24 \mathrm{~h}$ dietary recalls at the start (day -1 to day 3 ) and the end (day 29 to day 33 ) of the study.

\section{Nutritional assessment}

All patients were nutritionally assessed twice, at the beginning of the study and 1 month later, by measurement of body weight, muscular mid-arm circumference (MMAC) and skinfolds at the biceps, triceps (TST), subscapular and suprailiac sites. The percentage body fat was calculated using the formula of Durnin \& Womersley (1974). The height-creatinine index was derived from the patients' height and urinary creatinine excretion and expressed as a percentage of normal (Bistrian et al. 1975). 


\section{Biochemical measurements}

A blood sample was collected after an overnight fast on the same day as the nutritional assessment. A portion was frozen at $-18^{\circ}$. Alanine aminotransferase (ALT; EC 2.6.1.2), aspartate aminotransferase (AST; EC 2.6.1.1), alkaline phosphatase (ALP; EC 3.1.3.1), $\gamma$-glutamyl transferase (GGT; EC 2.3.2.2) and total bilirubin were measured immediately after blood collection, on a Monarch analyser (Instrumentation Laboratory, Lexington, MA, USA), using available commercial kits. The inter-assay coefficients of variation were below $2 \%$ for enzymes and equal to $2 \%$ for bilirubin. Coagulation tests including prothrombin time and proaccelerin expressed as percentage of normal were performed on a ST4 analyser (Stago, Asnières, France). On the other hand, total cholesterol, HDLcholesterol after precipitation by addition of phosphotungstic acid and $\mathbf{M g C l}_{\mathbf{2}}$ (LopesVirella et al. 1977), triacylglycerols, apolipoproteins Al (ApoA1) and B (ApoB), albumin, transthyretin, orosomucoid and $\mathrm{C}$-reactive protein (CRP) were measured in a single run on the Monarch analyser in thawed day 0 and day 30 samples. The intra-assay coefficients of variation were below $2 \%$ for lipid indices and $5 \%$ for proteins.

\section{Statistical analysis}

Results were expressed as means with their standard errors. They were interpreted according to normal ranges established in our laboratory using data from healthy hospital staff members. The paired Student's $t$ test was used for comparison of data at day $0 v$. day 30 , and the unpaired $t$ test was used for comparison of data between two groups of patients. Correlations were calculated according to the least square regression method. A $P$ value equal to or less than 0.05 was considered to represent a significant difference.

\section{RESULTS}

Dietary recalls as presented in Table 1 showed that at the start of the study our patients received satisfactory energy and protein intakes. They increased moderately by $10 \%$ after 1 month $(P<0 \cdot 001)$. MMAC values of all patients were below the 5 th percentile of their distribution in a healthy reference population while TST values were below the 5th percentile in fifteen patients (Bishop et al. 1981). There were no significant changes in weight throughout the study month while height-creatinine index, MMAC, TST and particularly fat mass improved (Table 2).

Liver function tests of the patients are presented in Table 3. At the start of the study, mean ALT level stood in the normal range while the mean values of the other enzymes studied (AST, PAL and GGT) were slightly above the normal range. After 1 month controlled oral nutrition, only AST and GGT decreased significantly $(P<0.05$ and $P<0.02$ respectively). However, changes in AST and ALT between day 0 and day 30 behaved similarly ( $r 0.481, P<0.01)$. Our cirrhotic patients showed moderately high concentrations of total bilirubin and low values for prothrombin time and proaccelerin. At the end of the study the mean values of bilirubin decreased while those for prothrombin time increased modestly but significantly. Variations of proaccelerin correlated positively with those of prothrombin time $(r 0.457, P<0.01)$ and negatively with those of total bilirubin $(r-0.447$, $P<0.01$ ).

In the present study two visceral proteins (albumin and transthyretin) on the one hand and two acute-phase reactants (CRP and orosomucoid) on the other hand were assessed (Table 4). Thirteen patients were infused with albumin. In the remaining non-ascitic patients, serum albumin levels improved slightly in the course of the study, as shown in Table 4. Transthyretin serum levels were sharply reduced in our patients and correlated positively with albumin $(r 0.569, P=0.001)$ and prothrombin time values $(r 0.439$, 
Table 1. Changes in energy and protein intake by cirrhotic patients after 1 month of regular oral nutrition

\begin{tabular}{|c|c|c|c|c|}
\hline & \multicolumn{2}{|c|}{ Day 0} & \multicolumn{2}{|c|}{ Day 30} \\
\hline & Mean & SEM & Mean & SEM \\
\hline Energy intake $(\mathrm{kJ} / \mathrm{kg}$ per $\mathrm{d})$ & 160 & 9 & $174^{*}$ & 8 \\
\hline Energy intake $(\mathrm{MJ} / \mathrm{d})$ & $9 \cdot 3$ & 0.4 & $10 \cdot 3 * * *$ & 0.4 \\
\hline Protein intake $(\mathrm{g} / \mathrm{d})$ & $79 \cdot 9$ & $3 \cdot 4$ & $88 \cdot 9 * * *$ & $3 \cdot 1$ \\
\hline
\end{tabular}

Mean values were significantly different from those for day $0: * P<0.02$, *** $P<0.001$ (paired Student's $t$ test).

Table 2. Changes in anthropometric variables in cirrhotic patients after 1 month of regular oral nutrition

\begin{tabular}{lccccc}
\hline & \multicolumn{2}{c}{ Day 0} & & \multicolumn{2}{c}{ Day 30 } \\
\cline { 5 - 6 } & Mean & SEM & & Mean & SEM \\
\hline Weight (kg) & $60 \cdot 6$ & $2 \cdot 2$ & & $60 \cdot 8$ & $1 \cdot 7$ \\
MMAC (mm) & 211 & $4 \cdot 0$ & & $218^{* *}$ & $4 \cdot 0$ \\
TST (mm) & $7 \cdot 8$ & $0 \cdot 8$ & & $9 \cdot 1^{* *}$ & $0 \cdot 8$ \\
Fat mass (\%) & $16 \cdot 8$ & $1 \cdot 2$ & & $18 \cdot 8^{* * *}$ & $1 \cdot 2$ \\
Height-creatinine index (\%) & $61 \cdot 1$ & $3 \cdot 0$ & & $68 \cdot 6^{* *}$ & $2 \cdot 4$ \\
\hline
\end{tabular}

MMAC, muscular mid-arm circumference; TST, tricipital skinfold thickness.

Mean values were significantly different from those of day $0: * * P<0.01,{ }^{* *} P<0.001$ (paired Student's $t$ test).

Table 3. Changes in biological indicators of liver function in cirrhotic patients during 1-month hospitalization

\begin{tabular}{|c|c|c|c|c|c|}
\hline & \multicolumn{2}{|c|}{ Day 0} & \multicolumn{2}{|c|}{ Day 30} & \multirow[b]{2}{*}{ Normal range } \\
\hline & Mean & SEM & Mean & SEM & \\
\hline $\operatorname{ALT}(\mathrm{U} / 1)$ & 28 & 3 & 25 & 3 & $5-40$ \\
\hline AST (U/1) & 46 & 5 & $41 *$ & 5 & $6-30$ \\
\hline ALP (U/l) & 112 & 10 & 113 & 10 & $30-100$ \\
\hline GGT (U/1) & 113 & 24 & $101^{* *}$ & 25 & $6-40$ \\
\hline Total bilirubin $(\mu \mathrm{mol} / \mathrm{l})$ & 44 & 7 & $36^{*}$ & 5 & $<20$ \\
\hline Prothrombin time $(\%)$ & 46 & 3 & $49^{*}$ & 3 & $80-100$ \\
\hline Proaccelerin $(\%)$ & 55 & 4 & 55 & 3 & $80-100$ \\
\hline
\end{tabular}

ALT, alanine aminotransferase (EC 2.6.1.2); AST, aspartate aminotransferase (EC 2.6.1.1); ALP, alkaline phosphatase (EC 3.1.3.1); GGT, $\gamma$-glutamyl transferase (EC 2.3.2.2).

Mean values were significantly different from those for day $0:{ }^{*} P<0.05$, ${ }^{* *} P<0.02$ (paired Student's $t$ test).

$P<0.02$ ). They did not change significantly during the study. Mean CRP value was slightly increased in our patients on entry into the study. Orosomucoid and CRP values decreased significantly by the end of the study $(P<0.001$ and $P<0.01$ respectively). Changes in orosomucoid values correlated positively with those in CRP $(r 0.605, P<0.001)$ and negatively with those in transthyretin $(r-0.399, P<0.05)$.

At the start of the study six patients were in group A of Child classification, ten in group 
Table 4. Changes in nutritional and inflammatory serum proteins in cirrhotic patients during 1-month hospitalization

\begin{tabular}{|c|c|c|c|c|c|}
\hline & \multicolumn{2}{|c|}{ Day 0} & \multicolumn{2}{|c|}{ Day 30} & \multirow[b]{2}{*}{ Normal range } \\
\hline & Mean & SEM & Mean & SEM & \\
\hline Albumin $(g / 1)$ & & & & & $35-48$ \\
\hline Patients with ascites $(n$ 13) & $25 \cdot 2$ & $1 \cdot 1$ & $26 \cdot 9 *$ & $1 \cdot 1$ & \\
\hline Patients without ascites $(n 17)$ & 27.6 & 0.7 & $29 \cdot 2^{*}$ & 0.9 & \\
\hline Transthyretin $(\mathrm{g} / \mathrm{l})$ & 0.09 & 0.01 & 0.09 & 0.01 & $0 \cdot 20-0 \cdot 35$ \\
\hline Orosomucoid $(\mathrm{g} / \mathrm{l})$ & 0.56 & 0.06 & $0 \cdot 43 * * *$ & 0.04 & $0 \cdot 40-1 \cdot 00$ \\
\hline C-reactive protein $(\mathrm{mg} / \mathrm{l})$ & 10 & 2 & $6^{* *}$ & 1 & $<6$ \\
\hline
\end{tabular}

Mean values were significantly different from those of day $0: * P<0.05, * * P<0.01, * * * P<0.001$.

Table 5. Changes in serum lipid and apolipoprotein patterns in cirrhotic patients during 1-month hospitalization

\begin{tabular}{|c|c|c|c|c|c|}
\hline & \multicolumn{2}{|c|}{ Day 0} & \multicolumn{2}{|c|}{ Day 30} & \multirow[b]{2}{*}{ Normal range } \\
\hline & Mean & SEM & Mean & SEM & \\
\hline Total cholesterol (mmol/l) & 3.84 & $0 \cdot 25$ & $4 \cdot 05$ & $0 \cdot 24$ & $3 \cdot 80-6 \cdot 30$ \\
\hline HDL-cholesterol (mmol/1) & 0.63 & 0.06 & $0.74 *$ & 0.06 & $1 \cdot 20-1 \cdot 70$ \\
\hline Triacylglycerols (mmol/1) & 0.96 & 0.07 & 0.95 & 0.05 & $0.50-1.60$ \\
\hline ApoAl $(\mathrm{g} / \mathrm{l})$ & 0.71 & 0.04 & $0.82 * * *$ & 0.04 & $1 \cdot 00-1 \cdot 70$ \\
\hline $\mathrm{ApoB}(\mathrm{g} / 1)$ & 0.53 & 0.03 & 0.53 & 0.03 & $0.50-0.90$ \\
\hline
\end{tabular}

HDL, high-density lipoprotein; Apo, apolipoprotein.

Mean values were significantly different from those of day $0:{ }^{*} P<0.02,{ }^{* *} P<0.001$.

B and fourteen in group C. Pugh score decreased at the end of the study $(9.2$ (SE 0.4) v. 8.5 (SE 0.4$), P<0.05$ ). It improved in twenty patients, remained unchanged in six and worsened in four.

Serum lipid indices are given in Table 5. Hypocholesterolaemia was not so severe when considered totally as in the HDL fraction. Both total and HDL-cholesterol increased at the end of the study but the difference reached statistical significance only with HDLcholesterol $(P<0.02)$. Triacylglycerol values stood in the normal range and did not change throughout the study. Mean ApoAl level was far below the normal range while mean ApoB level was at the lower limit of the normal range. In the course of the study ApoAl values increased significantly $(P<0.001)$ while ApoB values remained constant. ApoAl variations between day 0 and day 30 correlated positively with those of total cholesterol ( $r 0.645, P<0.001)$ and of HDL-cholesterol $(r 0.630, P<0.001)$.

Regression analysis was also performed between ApoA1 and HDL-cholesterol as indicators of lipid metabolism on the one hand, and various biochemical indicators of liver function on the other hand, in terms of values at the start of the study and changes during the study. As shown in Table 6, ApoAl correlated with five tests: total bilirubin, AST, prothrombin time, albumin and transthyretin while HDL-cholesterol correlated with only two tests: albumin and transthyretin. A positive correlation was observed between changes in transthyretin and those in total cholesterol and HDL-cholesterol $(r 0.439, P<0.02$ and $r 0.389, P<0.05$ respectively). 
Table 6. Correlations (r values) of serum indices of lipid metabolism with biochemical indicators of hepatic function in cirrhotic patients

\begin{tabular}{lcc}
\hline & Apo Al & HDL-cholesterol \\
\hline Total bilirubin & $-0.466^{* *}$ & -0.291 \\
Prothrombin time & $0.489^{* *}$ & 0.352 \\
Proaccelerin & 0.241 & 0.118 \\
Albumin & $0.539^{* *}$ & $0.537^{* *}$ \\
Transthyretin & $0.701^{* * *}$ & $0.590^{* * *}$ \\
AST & $-0.366^{*}$ & -0.356 \\
\hline
\end{tabular}

Apo, apolipoprotein; HDL, high-density lipoprotein; AST, aspartate aminotransferase (EC 2.6.1 1).

${ }^{*} P<0.05,{ }^{* *} P<0.01,{ }^{* * *} P<0.001$.

Table 7. Changes in mutritional and biochemical indices in cirrhotic patients according to their improvement in fat mass after I month hospitalization $\uparrow$

\begin{tabular}{|c|c|c|c|c|c|c|c|c|}
\hline & \multicolumn{4}{|c|}{ Group $1(n 18)$} & \multicolumn{4}{|c|}{ Group $2(n 12)$} \\
\hline & \multicolumn{2}{|c|}{ Day 0} & \multicolumn{2}{|c|}{ Day 30} & \multicolumn{2}{|c|}{ Day 0} & \multicolumn{2}{|c|}{ Day 30} \\
\hline & Mean & SEM & Mean & SEM & Mean & SEM & Mean & SEM \\
\hline Fat mass (\%) & $14 \cdot 6$ & $1 \cdot 5$ & $17 \cdot 9 * * *$ & 1.7 & $20 \cdot 0$ & $1-7$ & $20 \cdot 1$ & 1.5 \\
\hline MMAC (mm) & 209 & 6.0 & 213 & $5 \cdot 0$ & 215 & $7 \cdot 0$ & $225^{* *}$ & $7 \cdot 0$ \\
\hline Height-creatinine index (\%) & 60.7 & $3 \cdot 1$ & $67 \cdot 4^{*}$ & $3 \cdot 3$ & 61.8 & $6 \cdot 2$ & $70 \cdot 6$ & $3 \cdot 5$ \\
\hline Energy intake $(\mathrm{kJ} / \mathrm{kg}$ per d) & 167 & 12 & $183^{*}$ & 10 & 150 & 11 & 160 & 12 \\
\hline GGT (U/1) & 123 & 38 & 114 & 41 & 97 & 19 & $81^{*}$ & 13 \\
\hline Total bilirubin $(\mu \mathrm{mol} / 1)$ & 42 & 10 & 37 & 8 & 46 & 9 & 34 & 5 \\
\hline Prothrombin time $(\%)$ & 47 & 4 & $52^{*}$ & 4 & 43 & 3 & 44 & 3 \\
\hline Albumin $(\mathrm{g} / \mathrm{l})$ & $26 \cdot 4$ & 0.9 & $28 \cdot 2 * *$ & $1 \cdot 1$ & $27 \cdot 0$ & 0.9 & $28 \cdot 1$ & 0.9 \\
\hline Child-Pugh score & 8.9 & $2 \cdot 2$ & 8.4 & $2 \cdot 2$ & $9 \cdot 7$ & 2.5 & 8.7 & $2 \cdot 3$ \\
\hline Total cholesterol $(\mathrm{mmol} / \mathrm{l})$ & 3.75 & 0.33 & 4.08 & 0.33 & 3.98 & 0.39 & 4.01 & $0 \cdot 34$ \\
\hline HDL-cholesterol $(\mathrm{mmol} / 1)$ & 0.65 & 0.08 & $0.82 *$ & 0.09 & 0.59 & 0.09 & 0.62 & 0.07 \\
\hline ApoAl $(\mathrm{g} / \mathrm{l})$ & 0.74 & 0.06 & $0.87^{* * *}$ & 0.06 & 0.67 & 0.06 & 0.73 & 0.06 \\
\hline
\end{tabular}

MMAC, muscular mid-arm circumference; GGT, $\gamma$-glutamyl transferase (EC 2.3.2.2); HDL, high-density lipoprotein; Apo, apolipoprotein.

Mean values were significantly different from those of day $0:{ }^{*} P<0.05,{ }^{* *} P<0.01,{ }^{* * *} P<0.001$.

$\dagger$ Group 1 included patients who had increased their fat mass by more than $10 \%$; group 2 included patients whose fat mass increased by less than $10 \%$ or decreased.

Finally, looking at anthropometric variables, we studied the relationship between the improvement of the nutritional status and the changes in biochemical indices. Because the highest increase was observed with fat mass we divided our patient population into two groups: group 1 ( $n=18$; three women and fifteen men) improved fat mass by more than $10 \%$ of the initial value ( 24 (SE 3$) \%$ ), group 2 ( $n=12$; three women and nine men) did not improve and in some cases even worsened fat mass (2 (SE 3$) \%$ ). The two groups did not differ significantly in terms of age $(52.5$ ( $\mathrm{SE} 2 \cdot 2) v .48 .7$ ( $\mathrm{SE} 2 \cdot 8)$ years). There were seven ascitic patients in group 1 and six in group 2. As shown in Table 7, group 1 had significantly lower values of fat mass at day $0(14.6$ (SE 1.2) v. 20.0 (SE 1.1)\%, $P<0.05)$. At the end of the study the two groups of patients slightly improved their fat-free mass in terms of MMAC for group 2 and height-creatinine index for group 1. On admission to the study there was a trend for a higher energy intake in group 1 but the difference between the two 
groups was not significant. The intake increased significantly in group 1 throughout the study. Pugh score was not significantly lower in group 1. Six out of eighteen patients in group 1 and eight out of twelve in group 2 were in class $C$ of Child classification. Finally, the two groups did not differ on the basis of any biochemical index. However, by the end of the study GGT decreased significantly in group 2 while HDL-cholesterol, ApoAl and prothrombin time increased significantly in group 1.

\section{DISCUSSION}

The high rate of malnutrition in alcoholic liver cirrhosis points out the importance of nutritional support in patients admitted to hospital. The cirrhotic patients who participated in the present study were severely malnourished according to evaluations made using anthropometric measures. An improvement in fat mass and, to a lesser extent, in MMAC and height-creatinine index was observed after 1 month of regular oral diet. Therefore, our results show that cirrhotic patients may improve fat mass in preference to lean body mass, which suggests that malnutrition does not affect the different body compartments to the same extent in cirrhotic patients, as reported by Lautz et al. (1992). The preservation of fat mass may be related to hyperinsulinaemia which is frequently observed in this disease and which is known to promote fat storage. Other investigators have also reported improved anthropometric variables in patients either fed with a regular oral diet alone or supplemented with enteral (Kearns et al. 1992), parenteral (Mezey et al. 1991) or oral nutrition (Hirsch et al. 1993). It is important to note that our patients who received the standard hospital diet providing about $167 \mathrm{~kJ} / \mathrm{kg}$ per $\mathrm{d}$ were vigorously encouraged to eat all meals served and were not anorectic. Therefore, despite the severity of their disease, their spontaneous dietary intake was relatively good so that they consumed adequate amounts of energy. The amount of protein was particularly high but was well tolerated by our patients. The lack of clear-cut positive results in some studies may be partly related to an insufficient energy intake. Cabre et al. (1990) did not observe significant changes in anthropometric variables when giving enteral nutrition supplying $8849 \mathrm{~kJ} / \mathrm{d}$ to cirrhotics. Therefore, regardless of the mode of administration of short-term nutritional support, the energy intake required to improve nutritional status may be estimated as $167 \mathrm{~kJ} / \mathrm{kg}$ per d.

The second aim of the present study was to determine whether changes in nutritional status were associated with improved liver function. We observed slight decreases in AST, GGT and bilirubin and an increase in prothrombin time after $30 \mathrm{~d}$ hospital diet. The findings in the literature are not all concordant. Some investigators have detected no improvement in liver function tests after nutritional support (Christie et al. 1985). Naveau et al. (1986) obtained, after 1 month of therapy, equivalent diminutions of AST and bilirubin both in the orally fed group and in the group receiving supplementary parenteral nutrition. More recently, Hirsch et al. (1993) reported the same results in out-patients regardless of whether they were orally supplemented or not for 1 year with a casein preparation. On the other hand, the increase in prothrombin time in our patients is concordant with the results of Hirsch et al. (1993) whereas Naveau et al. (1986) reported no change in coagulation tests in all patients. All in all, the variations described for these variables are often moderate and not always concordant. This suggests that the hepatocellular functions reflected by the coagulation tests possibly need several months for reparation to start and that a clear decrease in AST or bilirubin which rather indicate liver injury can be obtained only when the nutritional support continues for long enough.

In the present study two visceral proteins which are considered reliable indicators of malnutrition were measured. Serum albumin levels increased modestly while transthyretin levels did not change throughout the study. CRP and orosomucoid levels decreased 
significantly, indicating an improvement of the inflammatory state. Serum albumin levels did not correlate with any other studied test of liver function. Transthyretin concentration correlated well with other indicators of liver function, suggesting that it may be more an index of the degree of liver damage rather than a nutritional variable. However, the synthesis of these two proteins is negatively regulated by interleukin- 6 which is secreted by monocytes and macrophages whereas the synthesis of CRP and orosomucoid is induced by the same interleukin (Kushner, 1988; Heinrich et al. 1990). Accordingly, low serum levels of albumin and transthyretin resulting from infections, i.e. spontaneous bacterial peritonitis which occurs frequently in cirrhotics, may lead to misinterpretation if an assessment of the inflammatory proteins is not available. Therefore, these proteins do not appear to be specific and sensitive markers of nutritional status or liver function.

The most striking finding in the present study was the change in the profile of lipid indices. In concordance with previous studies (Rubies-Prat et al. 1982; Duhamel et al. 1984; Tateossian et al. 1985; Poynard et al. 1986) we observed sharply decreased levels of HDL-cholesterol and ApoAl in our patients. ApoAl and to a lesser extent HDLcholesterol correlated with other indicators of liver function, data which concur with those previously described (Tateossian et al. 1985; Poynard et al. 1986). After a 1-month followup, of all variables studied, only ApoAl and HDL-cholesterol concentrations increased significantly. Moreover, changes in cholesterol and HDL-cholesterol correlated with those in transthyretin. When we divided our patient population into two groups according to the percentage increase in fat mass, we found that the changes in the lipid profile were more marked in patients who had improved their fat mass more obviously. The extent of liver failure in terms of biological indices was similar in both groups although the degree of severity of the disease evaluated by Child-Pugh score tended to be lower in group 1. It should be noted that these patients received a slightly higher energy intake than those who did not improve their fat mass. Moreover, their intake improved throughout the study. These results strongly suggest that the changes in biological tests observed were closely related to the improvement of the nutritional status due to the dietary intervention.

The drop in HDL level is attributed to an increased catabolism of HDL in patients with severe alcoholic hepatitis (Nestel et al. 1980). Whether or not cirrhotic patients show the same metabolic abnormality is not known. The decrease in HDL level in liver cirrhosis results mainly from a reduction in the $\mathrm{HDL}_{3}$ subclass despite a compensatory increase in $\mathrm{HDL}_{2}$; this effect becomes more marked with progressive liver injury (Duhamel et al. 1984). The increased $\mathrm{HDL}_{2}: \mathrm{HDL}_{3}$ ratio may consequently be due to a decreased activity of hepatic lipoprotein lipase (EC 3.1.1.34) which is synthesized by the liver and converts $\mathrm{HDL}_{2}$ into $\mathrm{HDL}_{3}$. On the other hand, the close relationship of HDL-cholesterol with the degree of liver injury argues in favour of a defect in the hepatocellular synthesis of $\mathrm{HDL}_{3}$ cholesterol. Therefore, the increase in HDL-cholesterol that we observed may result from an improved hepatic synthesis of $\mathrm{HDL}_{3}$-cholesterol or hepatic lipoprotein lipase. Further investigation of these different subclasses of HDL-cholesterol in the follow-up of our patients may reveal useful information.

ApoA1 is the main protein constituent of HDL and is synthesized in the cells of the liver and small intestine. Its decrease has been widely reported in liver cirrhosis and has been proposed as a marker of fibrosis (Poynard et al. 1986). It is thought to result from the replacement of hepatocytes by fibrous tissue in keeping with progressive hepatocyte dysfunction and necrosis (Poynard et al. 1986). The increase in serum ApoA1 that we observed at the end of our study possibly results from an improved hepatic synthesis of the apolipoprotein. On the other hand, a major determinant of the apolipoprotein level is the conversion from proApoA1. In fact, ApoAl is secreted into the plasma as proapolipoprotein $A 1$, which is converted into the mature ApoA1 by a protease named proApoA1 
converting enzyme (Edelstein et al. 1983; Zannis et al. 1983). The proApoA1 is higher in the plasma of patients with liver cirrhosis than in normal subjects. This seems to be caused by an impairment in the activity of the converting enzyme, in keeping with the progression of hepatic cell damage (Suehiro et al. 1993). Therefore, our findings may be interpreted as a better conversion of proApoA 1 resulting from an increased production of the enzyme due to improved liver function. This increase in ApoAl contrasted with the lack of change in the other usual indicators of hepatic synthesis and suggests that this protein may be a more sensitive index of improved hepatic function. Our findings are in line with those of Malmendier et al. (1992) who recommend the assessment of ApoA1 and ApoA2 in patients having undergone liver transplants to follow-up the restoration of liver function.

In conclusion, the present study shows that adequate oral nutrition makes possible an improvement in the nutritional status in cirrhotics with a preserved appetite, after 1 month of hospitalization. Instead of the long-established liver function tests such as AST, ALT and bilirubin which indicate only liver injury, or prothrombin time, proaccelerin and visceral proteins whose hepatic synthesis may need a longer time to be restored, ApoA1 and HDL-cholesterol appear to be earlier indicators in detecting the start of an improvement in liver function.

We thank J. Harper, Laboratoire de Langues, Faculté de Pharmacie, F-92296, ChâtenayMalabry, France, for revising the English of the manuscript.

\section{REFERENCES}

Bishop, C. W., Bowen, P. E. \& Ritchey, S. J. (1981). Norms for nutritional assessment of American adults by upper arm anthropometry. American Journal of Clinical Nutrition 34, 2530-2539.

Bistrian, B. R., Blackburn, G. L., Sherman, M. \& Scrimshaw, N. S. (1975). Therapeutic index of nutritional depletion in hospitalized patients. Surgery, Gynecology and Obstetrics 141, 512-516.

Cabre, E., Gonzalez-Huix, A., Abad-Lacruz, A., Esteve, M., Acero, D., Fernandez-Banares, F., Xiol, X. \& Gassull, M. A. (1990). Effect of total enteral nutrition on the short-term outcome of severely malnourished cirrhotics. Gastroenterology $98,715-720$.

Christie, M. L., Sack, D. M., Pomposelli, J. \& Horst, D. (1985). Enriched branched-chain amino acid formula versus a casein-based supplement in the treatment of cirrhosis. Journal of Parenteral and Enteral Nutrition 9 , $671-678$

Cordova, C., Musca, A., Violi, F., Alessandri, C. \& Iuliano, L. (1984). Apolipoprotein AI, AII and B in chronic active hepatitis and liver cirrhotic patients. Clinica Chimica Acta 137, 61-66.

Duhamel, G., Nalpas, B., Goldstein, S., Laplaud, M., Berthelot, P. \& Chapman, J. (1984). Plasma lipoprotein and apolipoprotein profile in alcoholic patients with and without liver disease: on the relative roles of alcohol and liver injury. Hepatology 4, 577-585.

Durnin, J. V. G. A. \& Womersley, J. (1974). Body fat assessed from total body density and its estimation from skinfold thickness: measurements on 481 men and women aged from 16 to 72 years. British Journal of Nutrition 32, 77-97.

Edelstein, C., Gordon, J. 1., Toscas, K., Sims, H. F., Strauss, A. W. \& Scanu, A. M. (1983). In vitro conversion of proapoprotein A-I to apoprotein A-I. Journal of Biological Chemistry 258, 11430-11433.

Heinrich, P. C., Castell, J. V.\& Andus, T. (1990). Interleukin-6 and the acute phase response. Biochemical Journal 265, 621-636.

Hirsch, S., Bunout, D., de la Maza, P., Iturriaga, H., Petermann, M., Icazar, G., Gattas, V. \& Ugarte, G. (1993). Controlled trial on nutrition supplementation in outpatients with symptomatic alcoholic cirrhosis. Journal of Parenteral and Enteral Nutrition 17, 119-124.

Kanel, G. C., Radvan, G. \& Peters, R. L. (1983). High-density lipoprotein cholesterol and liver disease. Hepatology 3, 343-348.

Kearns, P. J., Young, H., Garcia, G., Blaschke, T., O’Hanlon, G., Rinki, M., Sucher, K. \& Gregory, P. (1992). Accelerated improvement of alcoholic liver disease with enteral nutrition. Gastroenterology 102, $200-205$.

Keohane, P. P., Attrill, H., Grimble, G., Spiller, R., Frost, P. \& Silk, D. B. A. (1983). Enteral nutrition in malnourished patients with hepatic cirrhosis and acute encephalopathy. Journal of Parenteral and Enteral Nutrition 7, 346-350.

Kushner, I. (1988). The acute phase response: an overview. Methods in Enzymology 163, 373-383.

Lautz, H. U., Selberg, O., Körberg, J., Bürger, M. \& Müller, M. J. (1992). Protein-calorie malnutrition in liver cirrhosis. Clinical Investigator 70, 478-486. 
Lopes-Virella, M. F., Stone, P., Ellis, S. \& Caldwell, J. A. (1977). Cholesterol determination in high-density lipoproteins separated by three different methods. Clinical Chemistry 23, 882-884.

Malmendier, C. L., Lontie, J. F., Mathé, D., Adam, R. \& Bismuth, H. (1992). Lipid and apolipoprotein changes after orthotopic liver transplantation for end-stage liver diseases. Clinica Chimica Acta 209, 169-177.

Mendenhall, C. L., Tosch, T., Weesner, R. E., Garcia-Pont, P., Goldberg, S. J., Kiernan, T., Seef, L. B., Sorrell, M., Tamburro, C., Zetterman, R., Chedid, A., Chen, T. \& Rabin, L. (1986). VA cooperative study on alcoholic hepatitis. II. Prognostic significance of protein-calorie malnutrition. American Journal of Clinical Nutrition 43, 213-218.

Mezey, E., Caballeria, J., Mitchell, M. C., Pares, A., Franklin Herlong, H. \& Rodes, J. (1991). Effect of parenteral amino acid supplementation on short-term and long-term outcomes in severe alcoholic hepatitis: a randomized controlled trial. Hepatology 14, 1090-1096.

Naveau, S., Pelletier, G., Poynard, T., Attali, P., Poitrine, A., Buffet, C., Etienne, J. P. \& Chaput, J. C. (1986). A randomized clinical trial of supplementary parenteral nutrition in jaundiced alcoholic cirrhotic patients. Hepatology 6, 270-274.

Nestel, P. J., Tada, N. \& Fidge, N. H. (1980). Increased catabolism of high density lipoprotein in alcoholic hepatitis. Metabolism 29, 101-104.

Ostrowski, Z. L. (1978). Les Aliments. Table des Valeurs Nutritives. J. Lanore, ed. Paris.

Poynard, T., Abella, A., Pignon, J. P., Naveau, S., Leluc, R. \& Chaput, J. C. (1986). Apolipoprotein AI and alcoholic liver disease. Hepatology 6, 1391-1395.

Pugh, R. N. H., Murray-Lyon, I. M., Dawson, J. L., Pietroni, M. C. \& Williams, R. (1973). Transection of the oesophagus for bleeding oesophageal varices. British Journal of Surgery 60, 646 649.

Rubies-Prat, J., Masdeu, S., Nubiola, A. R., Chacón, P., Holguera, C. \& Masana, L. (1982). High-density lipoprotein cholesterol and phospholipids, and apoprotein $\mathrm{A}$ in serum of patients with liver disease. Clinical Chemistry 28, 525-527.

Silk, D. B. A. (1988). Parenteral nutrition in patients with liver disease. Journal of Hepatology 7, $269-277$.

Smith, J., Horowitz, J., Henderson, J. M. \& Heymsfield, S. (1982). Enteral hyperalimentation in undernourished patients with cirrhosis and ascites. American Journal of Clinical Nutrition 35, 56-72.

Suehiro, T., Yamamoto, M., Yoshida, K. \& Ohno, F. (1993). Increase of plasma proapolipoprotein A-1 in patients with liver cirrhosis and its relationship to circulating high-density lipoproteins 2 and 3 . Clinical Chemistry 39, 60-65.

Tateossian, S., Peynet, J. G., Legrand, A. G., Collet, B., Rossignol, J., Delattre, J. \& Rousselet, F. (1985). Variations in HDL and VLDL levels in chronic alcoholics. Influence of the degree of liver damage and of withdrawal of alcohol. Clinica Chimica Acta 148, 211-219.

Zannis, V. I., Karathanasis, S. K., Keutmann, H. T., Goldberger, G. \& Breslow, J. L. (1983). Intracellular and extracellular processing of human apolipoprotein A-I : secreted apolipoprotein A-I isoprotein 2 is a propeptide. Proceedings of the National Academy of Sciences of the United States of America 80, 2574-2578. 